\title{
Medicinal Plants Used in Management and Treatment of Alzheimer's Disease in Africa: An Insight into Therapeutic Avenues and Possible Development as Future Phytopharmaceuticals
}

\author{
F.G. OLORUNFEMI*, A.M. ADEWOLU \\ Department of Biochemistry, College of Medicine, University of Lagos, Nigeria
}

\begin{abstract}
Alzheimer's disease (AD) is a devastating neurodegenerative disorder which needs adequate studies on effective treatment options. The extracts of plants and their effect on the amelioration of AD symptoms have been extensively studied. This review summarizes the use of medicinal plants in treatments and management of Alzheimers disesase, its mechanisms and active primary metabolite responsible for its mode of action and possible future development of this plant extracts into phytopharmaceuticals. The medicinal plants used in management of Alzheimers disease in Africa particularly in Nigeria includes: Yizhi Jiannao, Moringa oleifera (Drumstick tree), Cassia obtisufolia (Sicklepod), Desmodium gangeticum (Sal Leaved Desmodium), Melissa offiffiffi cinalis (Lemon Balm), and Salvia offiffiffi cinalis (Garden sage, common sage).
\end{abstract}

Keywords: Alzheimer's disease, Antiamyloid aggregation, Antioxidants, Acetyl choline esterase inhibitor, Plant extracts.

DOI: $10.7176 / \mathrm{JNSR} / 10-10-04$

Publication date:May $31^{\text {st }} 2020$

\subsection{INTRODUCTION}

\subsection{MEDICINAL PLANTS}

Herbal medicines and natural products are the oldest remedies known to mankind. Medicinal plants have been used by all cultures throughout the history. In present scenario, the demand for herbal products is growing, exponentially throughout the World. In human body, the nervous system coordinates and regulates the various voluntary and involuntary activities of the body. The central nervous system and the autonomic nervous system are interlinked and some drugs affect the CNS producing reactions associated with the autonomic system (McCorry, 2007). Drugs involved with the CNS may have general stimulatory or depressant action with anticonvulsant and psychopharmacological activities. Memory deficit is a major global health problem. Current therapies are inadequate and have numerous adverse effects. There is an urgent need for possible alternative treatments for $\mathrm{AD}$ and memory deficit. Various medicinal plants are prescribed to enhance the memory. We have reviewed the literature on medicinal plants used in the treatment of AD and memory deficit (Xu et al., 2009). Several medicinal plants have been used for decades in different cultures to improve memory such as Valeriana officinalis, Punica granatum L., Salvia of-ficinalis, Myristica fragrans Bacopa monnieri Linn, Centella asiatica Linn and Evolvulus alsinoides Linn. Elufioye et al. (2012) reported some plants used as anti-aging and memo-ry enhancing activities in Sagamu, Nigeria that are Bacopa floribunda, Angraecum eichlerianum, Parquet inanigrescens, Cleome gynandra, Dalbergia lacteal, Capsicum fructescens, Aframomum melegueta, Digitaria debilis, Musa sapientum, Bryophyllum pinnatum, Abrus precatorius, Ficus exasperate, Dioscorea mangenotiana, Jatropha curcas, Spondia smombin, Capsicum frutescens, Cola acuminate, Mirabilis jalapa, Elaies guineensis, Canna indica, Ipomoea mauritania, Bambusa vul-garis, Cordia millenii, Piper guineense, Dioclea sarmentosa, Cucumeropsis mannii, Eleusine indica, Ocimum basilicum, Khaya ivorensis, Carpolobia alba, Carapa procera, Entandro-phragma utile, Xylopiaae thiopica, Garcinia kola, Theobroma cacao, Milicia excels, Blighia sapida, Baphia nitida, Peperomia pellucid, Vernonia amygdalina and Zea mays. Jazayeri et al. (2014) reported some plants having anticholinesterase ac-tivity such as Brassica alba, Brassica nigra, Camellia sinensis, Cinchona officinalis, Citrus aurantifolia, Citrus aurantium, Ferula assafoetida, Humulus lupulus, Juglans regia, Juniperus sabina, Myristica fragrans, Pelargonium graveolens, Pistacia vera, Punica granatum, Rheum officinale, Rosa damasce-na, Salix alba and Zizyphus vulgaris. Other plants having memory enhancing properties are Juglans regia (Haider et al., 2011), Cuminum cyminum (Koppula and Choi, 2011), Ficus religiosa (Kaur et al., 2010), Melissa officinalis (Kenne-dy and Scholey, 2006), Rosmarinus officinalis (Ozarowski et al., 2013), Piper nigrum (Hritcu et al., 2014), Ginkgo biloba (Tan et al., 2015), Bacopa monnieri (Roodenrys et al., 2002), Desmodium gangeticum (Mahajan et al., 2015) and Emblica officinalis Gaerth (Justin Thenmozhi et al., 2016). Herbal medicines have been used to treat various ailments in Unani system of medicine since ancient times. However, there is a lack of scientific data on the effectiveness and stability of bioactive chemical constituents in medicinal plants. In this review, we aimed at documenting the information on plants used as a memory enhancer in AD.Withania somniferaWithania somnifera belongs to the family Solanaceae. It $(500 \mathrm{mg} / \mathrm{d})$ exhibited calming effects on stress and reversed mem-ory loss 
(Auddy et al., 2008). Cholinergic activity of Witha-nia somnifera has been reported in a previous study (Schliebs et al., 1997). Memory enhancing activity and cognition im-proving property of Withania somnifera increase due to its ability to increase acetylcholine level in the brain. Neurotic outgrowth activity of Withania somnifera is reported already in human neuroblastoma cells that are time- and dose-de-pendent. Withania somnifera enhances dendrite and axon regeneration (Tomoharu et al., 2005). A molecular modeling study indicates that withanamides $A$ and $C$ bind to $A \beta$ and inhibit fibril synthesis (Jayaprakasam et al., 2010). Curcuma longaCurcuma longa belongs to the family Zingiberaceae. In Southeast Asian countries, prevalence of AD is low due to consumption of turmeric. It has anti-inflammatory activity that is also associated with reduced risk of AD (Aggarwal and Harikumar, 2009). Curcumin reduces the plaque depo-sition in the brain. Turmeric decreases oxidative stress and amyloid pathology (Mishra and Palanivelu, 2008). In one study, administration of low doses of curcumin reduced A $\beta$ level up to $40 \%$ in mice with $\mathrm{AD}$ as compared to control drug (Shytle et al., 2009). Curcumin at low doses caused $43 \%$ decrease in the plaque burden that these $\mathrm{A} \beta$ have on the brain of mice with $\mathrm{AD}$ (Mishra and Palanivelu, 2008). A previous study indicates that low doses of curcumin admin-istered for long duration are more effective in the treatment of $\mathrm{AD}$ as compared to higher doses of curcumin (Yang et al. 2005). Curcumin has an ability to bind with $\mathrm{A} \beta$ and inhibits its self assembly (Reinke and Gestwicki, 2007). Curcumin has powerful anti-inflammatory and antioxidant effects (Fan et al., 2015); according to the researchers, these effects help in treating Alzheimer's symptoms caused by inflammation and oxidation (Frautschy and $\mathrm{Hu}, 2001$ ). Hypercholesterolemia and hyperlipidemia increase amyloid plaques by intracellular accumulation of cholesterol esters (Tokuda et al., 2000). Sci-entists believe that curcumin might have therapeutic effects on AD by inhibiting cholesterol synthesis and reducing se-rum peroxides (Soni and Kuttan, 1992). Convolvulus pluricaulisConvolvulus pluricaulis belongs to the family Convolvulace-ae. It is used as a memory enhancing agent. A previous study has shown that aqueous and ethyl acetate extract of Convol-vulus pluricaulis increases memory functions and learning abilities (Bihaqi et al., 2011). In another study, a wide range of secondary metabolites such as steroids, anthocyanins, flavonol glycosides and triterpenoids have been isolated that are responsible for memory enhancing and nootropic prop-erties (Malik et al., 2011). Convolvulus pluricaulis has been repoted to calm the nerves by regulating the stress hormones synthesis (cortisol and adrenaline) in the body (Sethiya et al., 2009). The ethanolic extract of Convolvulus pluricaulis and its aqueous and ethyl acetate fractions significantly improved memory retention and learning abilities in rats (Nahata et al., 2008). Another study conducted by Bihaqi et al. (2011) indicated that extracts of Convolvulus pluricaulis enhance the memory in Wistar rats in a dose-dependent manner. Similarly, administration of Convolvulus pluricaulis for 1 week increased memory in aged mice (Sharma et al., 2010). Administration of Convolvulus pluricaulis increased the ace-tylcholinesterase activity in the hippocampal CA1 and CA3 regions associated with the memory function and learning abilities (Dubey et al., 1994). Centella asiatica Centella asiatica belongs to the family Apiaceae. It contains saponins, asiaticosides, madecassoside, madasiatic acid, brahmoside, brahminoside, sasiaticoside, sitosterol, tannins, ascorbic acid, centoic acid, centellic acid, thankuniside, brahmoside, brahminoside, siatic acid, thankuniside, gly-coside, triterpine, thankunic acid, vellarin, asiaticosides, thankuniside, and isothankuniside (Siddiqui et al., 2007). Centella asiatica is used in depression, rheumatism, mental weakness, abdominal pain, and epilepsy (Gohil et al., 2010). It is diuretic, anti-spasmodic, anti-convulsive, tonic, stimu-lant, emmenagogue, antioxidant and spermatogenic (Heidari et al., 2007). Centella asiatica reversed the A $\beta$ pathology and reduced oxidative stress response (Amala et al., 2012). Rao et al. (2007) reported that treatment with Centella asiatica (Linn) fresh leaf extract enhanced learning ability and memory retention power in Wistar rats. Adult rats of 2.5 months old were selected for this study. Three different doses $(2,4$, and $6 \mathrm{mg} / \mathrm{kg})$ of extracts were administered for 2, 4, and 6 weeks. Spatial learning (T-maze) and passive avoid-ance tests were performed after the treatment period. Results were compared with those of age matched control rats. Im-provement in spatial learning was significant at the dose of $6 \mathrm{~mL}$ of extract. The use of Centella anhanced memory retention that was evident from passive avoidance test. This data showed that Centella asiatica enhances learn-ing ability and memory retention power in adult rats. Veer-endra and Gupta (2003) reported efficacy of Centella asiaticain AD. Its cognition enhancing activities and anti-oxidant effects have been reported. Aqueous extract of Centella asi-atica (100, 200 and 300 $\mathrm{mg} / \mathrm{kg}$ ) was administered for 21 days in streptozotocin (STZ)-induced cognitive impairment and oxidative stress in rats. STZ at $3 \mathrm{mg} / \mathrm{kg}$ was intracerebroven-tricularly injected into male Wistar rats bilaterally on days 1 and 3 . Cognitive behavior was assessed after 13, 14 and 21 days of treatment. Rats were sacrificed for assessment of oxidative stress after 21 days of treatment. Cognitive behaviors of rats treated with Centella asiatica extract improved signifi-cantly. The maximum response was observed after adminis-tration of extract at the doses of 200 and 300 $\mathrm{mg} / \mathrm{kg}$. Results from Veerendra and Gupta (2003) showed that Centella asiatica is effective in STZ-induced cognitive impairment in rats. Celastrus paniculatus Celastrus paniculatus belongs to the family Celastraceae. It prevented neuronal cell damage against hydrogen peroxide toxicity due to its antioxidant activity (Godkar et al., 2006). Administration of Celastrus paniculatus prevents neuronal cell damage caused by glutamine induced toxicity (Godkar et al., 2003). Celastrus paniculatus increases cholinergic ac-tivity that contributes its ability to improving memory per-formance (Bhanumathy et al., 2010). Aqueous extract of Cel-astrus paniculatus has antioxidant and cognition enhancing properties (Kumar and Gupta, 2002). Celastrus paniculatusextracts protected 
neuronal cells against hydrogen peroxide induced toxicity in part by virtue of their antioxidant and free radical scavenging activities (Katekhaye et al., 2011). Nardostachys jatamansi Nardostachys jatamansi belongs to the family Caprifoliace-ae. It contains sesquiterpene valeranone that has been used for treatment of stress (Lyle et al., 2009). In a study, Nardo-stachys jatamansi exhibited memory retention and learning enhancing abilities in aged and young mice and reversed scopolamine and diazepam induced amnesia. Nardostachys jatamansi also reversed aging induced amnesia (Joshi and Parle, 2006). Karkada et al. (2012) reported efficacy of Nar-dostachys jatamansi in the prevention of stress induced memory deficit.Coriandrum sativum Coriandrum sativum belongs to the family Apiaceae. In one study, Coriandrum sativum was given for 45 days for its ef-ficacy on cognitive function in male Wistar rats. This study was conducted in comparison with aging, scopolamine and diazepam induced amnesia. Coriandrum sativum exhibited memory enhancing effects due to its antioxidant, anti-in-flammatory and cholesterol lowering activities (Vasudevan and Milind, 2009). Ficus carica Ficus carica belongs to the family Moraceae. It was investi-gated for its effect in retrieval, retention and acquisition of spatial recognition. Ficus carica contains quercetin that plays an important role in memory deficit and AD due to its anti-oxidant activity. For this study, mice with memory deficit and normal mice were used. Rectangular maze model and Y-maze were used to assess efficacy of Ficus carica on cognitive func-tions. Hexane extract (100 and $200 \mathrm{mg} / \mathrm{kg}$ ) was administered to adult swiss Wistar albino mice. In this study, Bacopa monniera and scopolamine were used as standard drug and amnestic agent respectively. Ficus carica $200 \mathrm{mg} / \mathrm{kg}$ exhibited maximum nootropic response that is near to response ex-hibited by a standard drug Bacopa monniera. In conclusion, Ficus carica at lower doses exhibits mild memory enhancing effet and higher doses evoke better learning ability and alter behavior (Saxena et al., 2013). Ginkgo biloba Ginkgo biloba belongs to the family Ginkgoaceae. It contains bilobalide that has a neuroprotective activity (Chandrase-karan et al., 2001). Ginkgo biloba decreases free radical and improves memory in patients with AD (Shi et al., 2010). It contains flavonoids that are involved in memory enhance-ment (Bastianetto et al., 2000). Gingko biloba prevents neurodegeneration and GABA inhibitory neurotransmis-sion induced by hippocampal corticosterone (Walesiuk and Braszko, 2009). Administration of Ginkgo biloba significantly improved memory and learning performance in albino rats (Nalini et al., 1992). Ilex paraguariensis Ilex paraguariensis belongs to the family Aquifoliaceae. It has a memory enhancing property. It contains vitamin B12, B1 and C. Ilex paraguariensis is being used as an anti-dementia agent (Bastos et al., 2007). Its memory enhancing property was investigated in different rat models (Colpo et al., 2007).

\subsubsection{Africa and use of Medicinal P;ants in Traditional Medicine}

The use of medicinal plants as a fundamental component of the African traditional healthcare system is perhaps the oldest and the most assorted of all therapeutic systems. In many parts of rural Africa, traditional healers prescribing medicinal plants are the most easily accessible and affordable health resource available to the local community and at times the only therapy that subsists. Nonetheless, there is still a paucity of updated comprehensive compilation of promising medicinal plants from the African continent. The major focus of the present review is to provide an updated overview of 10 promising medicinal plants from the African biodiversity which have short- as well as long-term potential to be developed as future phytopharmaceuticals to treat and/or manage the neurological disorder alzeheimers disease.

African traditional medicine is the oldest, and perhaps the most assorted, of all therapeutic systems. Africa is considered to be the cradle of mankind with a rich biological and cultural diversity marked by regional differences in healing practices [Aone Mokaila, 2001]. African traditional medicine in its varied forms is holistic involving both the body and the mind. The traditional healer typically diagnoses and treats the psychological basis of an illness before prescribing medicines, particularly medicinal plants to treat the symptoms [Gurib-Fakimet al., 2010]. The sustained interest in traditional medicine in the African healthcare system can be justified by two major reasons. The first one is inadequate access to allopathic medicines and western forms of treatments, whereby the majority of people in Africa cannot afford access to modern medical care either because it is too costly or because there are no medical service providers. Second, there is a lack of effective modern medical treatment for some ailments such as malaria and/or HIV/AIDS, and even neurodegenerative disease, alzeheimers disease which, although global in distribution, disproportionately affect Africa more than other areas in the world.

The most common traditional medicine in common practice across the African continent is the use of medicinal plants. In many parts of Africa, medicinal plants are the most easily accessible health resource available to the community. In addition, they are most often the preferred option for the patients. For most of these people, traditional healers offer information, counseling, and treatment to patients and their families in a personal manner as well as having an understanding of their patient's environment [Gurib-Fakim and Mahomoodally, 2013]. Indeed, Africa is blessed with enormous biodiversity resources and it is estimated to contain between 40 and 45,000 species of plant with a potential for development and out of which 5,000 species are used medicinally. This is not surprising since Africa is located within the tropical and subtropical climate and it is a known fact that plants accumulate important secondary metabolites through evolution as a natural means of surviving in a hostile environment [Manach et al., 20004]. The present review aims to explore some medicinal plants in Africa used for treatment of neurodegenerative diseases Alzheimers Disease. 


\subsection{Alzheimers Disease}

Alzheimer's disease (AD) is a neurodegenerative disease affecting older adults. In 1906, Alois Alzheimer, a German neuropathologist and psychiatrist discovered AD. About 24 million World population is suffering from dementia, in which majority of patients have AD (Ballard et al., 2011). AD is characterized by memory loss, behavior deterioration, performance impairment, and thought slowness. The condi-tion is mimicked by severe depression (Squire, 1992). Cog-nitive and neural dysfunction occurs due to accumulation of oxidative damage to nucleic acid, protein and mitochondria in the brain. In Spain, survey was conducted on 1,637 people above 64 years of age regarding subjective memory com-plaints (SMC). SMC were reported in 524 persons (32.4\%). Cognitive performance, mood, sex, education and age are associated with prevalence of SMC. SMC are reported in $24 \%$ of people between 65 and 69 years of age. SMC increase 57\% in people up to 90 years or above group. SMC are 52.8\% in people with anxiety and depression (Montejo et al., 2011). Severe psychological stress or drug use can cause amnesia. Various allopathic medicines are prescribed in AD but they exert side effects. Therefore, herbal medicine could be a good source of drugs for treatment of AD and memory defi-cit with fewer or no side effects. The present article reviews the medicinal plants that are proven for their efficacy to treat AD and memory deficits. Pathogenesis Two characteristic features are seen in the brain of patients with AD. 1. Senile plaques contain extracellular deposits of amy-loid-beta $(A \beta)$, a peptide synthesized by breakage of A $\beta$ pre-cursors (genetic locus 21q21-22). Abnormal deposits of $A \beta$ are also found in blood vessels.2. Neurofibrillary tangles, dense bundles of abnormal fi-bers in the cytoplasm of neurons which consist of an altered form of the microtubularassociated protein are found in pa-tients with AD (Hoyer, 1992; Iqbal et al., 2005; Kuljis, 2007; Fernandez et al., 2008; Bamburg and Bloom, 2009). Molecular MechanismThe main features of AD are extracellular A $\beta$ pathology and neurofibrillary tau pathology (tangles and threads). For 25 years, most studies have been conducted on the $A \beta$ hypothesis of AD pathogenesis and progression (Pimplikar, 2009). But because of failure in clinical trials of $A \beta-$ targeted treatment and the new concept of prion like propagation of intracellular abnormal proteins, tau has come back into the spotlight as a candidate therapeutic target in management of Alzheimer's disease. Tau pathologies are found in a range of neurodegenerative disorders, but extensive analyses of pathological tau in diseased brains has indicated that the abnormal tau protein in each disease is structurally distinct [Downloaded free from http://www.nrronline.org on Friday, April 3, 2020, IP: 197.210.84.30]661Akram and Nawaz. / Neural Regeneration Research. 2017;12(4):660-670.(Avila et al., 2004), supporting the concept that progres-sion of the diverse but characteristic tau pathologies occur through prion like seed dependent aggregation. Therefore, intervention in the conversion of normal tau to abnormal forms and in cell-to-cell transmission of tau may be the key for development of disease modifying treatment of AD and other memory deficits (Hasegawa, 2016).Drug TargetsThe tau and amyloid hypothesis has led to focus on tau and amyloid as treatment targets. The current therapeutic goals are to decrease amyloid levels and prevent amyloid toxicity/aggregation and tau aggregation/phosphorylation. AD has a heterogenous cause with a large percentage termed sporadic AD arising from unknown etiology and a smaller fraction of early onset familial AD caused by mutation in various genes, such as the persenilins (PS1, PS2) and $\beta$ amyloid precursor protein (APP) (Tang, 2003; Bird, 2008). Other genes such as apolipoprotein E (APOE) are considered to be a risk factor for AD (Kim et al., 2009). Various proteins such as APOE, APP, BACE (A $\beta$ cleaving enzyme), PS1/2, secretases and tau play an important role in the pathogenesis of AD. Therefore, research is focused to develop new inhibitors for PS1, BASE and secretase for treatment of AD. There is also a significant advancement in understanding the cholinesterase function in the brain and the use of cholinesterase inhibitors in management of AD (Wilkinson et al., 2004; Yiannopoulou and Papageorgiou, 2013). The mechanism of new generation of acetyl and butyryl cholinesterase inhibitors is being studied and investigated in clinical trials for AD (Grossberg, 2003). Other strategies, such as hormone therapy, anti-oxidants, cholesterol lowering agents, anti-inflammatory agents and vaccinations are also being investigated for treating AD (La-hiri et al., 2002). Drug Treatment The demonstration of damage to the cholinergic pathways in the brain leads to great interest in drug development. Ace-tylcholinesterase inhibitors are usually prescribed to treat AD. These drugs help in enhancing cognitive functions such as memory and thoughts. These medicines are effective in patients with mild to moderate AD (Houghton and Howes, 2005). Tacrine (a cholinesterase inhibitor) at a high dose $(160 \mathrm{mg} / \mathrm{d})$ was reportedly used in the treatment of AD (Schnei-der, 2000). Tacrine was investigated in both clinical trials and neuropsychological test scores, in a 30 week randomized placebo controlled trial (Knapp et al., 1994). However, the use of tacrine is limited due to adverse effects such as hepa-totoxicity (Watkins et al., 1994). Anti-oxidants are effective for AD because they aid in reducing the free radicals that damage the brain cells (Howes and Houghton, 2012). Probiotics have been reported for their efficacy to enhance memory (Lyte, 2011). Probiotics are used as antidepressant in AD. It reduces anxiety like behavior and attenuates psy-chological stress. Neurochemicals are produced by microbes. Immunological and neurological effects are induced by probiotics. Probiotics also have immunomodulating ac-tivity (Misra and Medhi, 2013). In Chinese and Ayurvedic medicines, medicinal plants are used to treat $\mathrm{AD}$, neurode-generative changes and cognitive diseases. Various western medicines being used in memory loss are derived from plants. Plant derived alkaloids such as anticholinesterase have been used to treat AD. In the United Kingdom, plant derived galantamine is also used in the treatment of 
neuro-degenerative disorders. Five million Americans are suffering from AD and this number will increase up to 7.7 million in 2030. Symptoms of neurodegenerative disorders clearly ap-pear after 60 years of age (Chengxuan et al., 2009). Etiology of neurodegenerative disorders is linked to genetic defect that is $10-15 \%$ of total cases. In $\mathrm{AD}$, loss of neurons appears in subcortical structure, cortex and hippocampus. Various compounds have been identified by phytochemical studies such as alkaloids, sterols, triterpenes, polyphenols, tannins, flavonoids and lignins that have pharmacological activities including anti-cholinesterase and anti-amyloidogenic. Medicinal plants are playing a significant role in the management of AD and memory deficit. The important traditional therapeutic methods are Ayurvedic, homeopathy, Unani and Sidha systems of medicine. Unani system of medicine offers traditionally a highly scientific health care therapy as a divine gift and as a result the global interest of the medical profession is focused on medicinal plants. Traditional system of medicine is fundamentally preventive, protective, nutritive and curative. Therefore, traditional medicines are safe and harmless which treat the patients with fewer or no side effects. Herbal medicines have their origins in ancient cultures, including those of the Egyptian, Indians and Chinese. It involves the use of medicinal plants to treat AD and enhances general health and well beings. In fact, many pharmaceutical drugs are based on the synthesized adaptations of naturally occurring compounds found in plants. In recent years, interest in herbal medicine has increased, leading to a greater scientific interest in the medicinal use of plants in treating disease and improving health, often without any significant side effects.

\subsection{Pathogenesis}

Two characteristic features are seen in the brain of patients with AD.

1. Senile plaques contain extracellular deposits of amyloid-beta $(A \beta)$, a peptide synthesized by breakage of $A \beta$ precursors (genetic locus 21q21-22). Abnormal deposits of $A \beta$ are also found in blood vessels.

2. Neurofibrillary tangles, dense bundles of abnormal fibers in the cytoplasm of neurons which consist of an altered form of the microtubular-associated protein are found in patients with AD (Hoyer, 1992; Iqbal et al., 2005; Kuljis, 2007; Fernandez et al., 2008; Bamburg and Bloom, 2009).

\subsection{Molecular Mechanism}

The main features of AD are extracellular A $\beta$ pathology and neurofibrillary tau pathology (tangles and threads). For 25 years, most studies have been conducted on the $\mathrm{A} \beta$ hypothesis of AD pathogenesis and progression (Pimplikar, 2009). But because of failure in clinical trials of A $\beta$-targeted treatment and the new concept of prion like propagation of intracellular abnormal proteins, tau has come back into the spotlight as a candidate therapeutic target in management of Alzheimer's disease. Tau pathologies are found in a range of neurodegenerative disorders, but extensive analyses of pathological tau in diseased brains has indicated that the abnormal tau protein in each disease is structurally distinct(Avila et al., 2004), supporting the concept that progression of the diverse but characteristic tau pathologies occur through prion like seed dependent aggregation. Therefore, intervention in the conversion of normal tau to abnormal forms and in cell-to-cell transmission of tau may be the key for development of disease modifying treatment of AD and other memory deficits (Hasegawa, 2016).

\subsection{Drug Targets}

The tau and amyloid hypothesis has led to focus on tau and amyloid as treatment targets. The current therapeutic goals are to decrease amyloid levels and prevent amyloid toxicity/ aggregation and tau aggregation/phosphorylation. $\mathrm{AD}$ has a heterogenous cause with a large percentage termed sporadic $\mathrm{AD}$ arising from unknown etiology and a smaller fraction of early onset familial AD caused by mutation in various genes, such as the persenilins (PS1, PS2) and $\beta$ amyloid precursor protein (APP) (Tang, 2003; Bird, 2008). Other genes such as apolipoprotein $\mathrm{E}(A P O E)$ are considered to be a risk factor for AD (Kim et al., 2009). Various proteins such as APOE, APP, BACE (A $\beta$ cleaving enzyme), PS1/2, secretases and tau play an important role in the pathogenesis of AD. Therefore, research is focused to develop new inhibitors for PS1, BASE and secretase for treatment of AD. There is also a significant advancement in understanding the cholinesterase function in the brain and the use of cholinesterase inhibitors in management of AD (Wilkinson et al., 2004; Yiannopoulou and Papageorgiou, 2013). The mechanism of new generation of acetyl and butyryl cholinesterase inhibitors is being studied and investigated in clinical trials for AD (Grossberg, 2003).

Other strategies, such as hormone therapy, anti-oxidants, cholesterol lowering agents, anti-inflammatory agents and vaccinations are also being investigated for treating AD (Lahiri et al., 2002).

\subsection{Management of Alzeheimers Diseae \\ 1.6.1. Drug Treatment}

The demonstration of damage to the cholinergic pathways in the brain leads to great interest in drug development. Acetylcholinesterase inhibitors are usually prescribed to treat AD. These drugs help in enhancing cognitive functions such as memory and thoughts. These medicines are effective in patients with mild to moderate AD 
(Houghton and Howes, 2005). Tacrine (a cholinesterase inhibitor) at a high dose (160 mg/d) was reportedly used in the treatment of AD (Schneider, 2000). Tacrine was investigated in both clinical trials and neuropsychological test scores, in a 30 week randomized placebo controlled trial (Knapp et al., 1994). However, the use of tacrine is limited due to adverse effects such as hepatotoxicity (Watkins et al., 1994). Anti-oxidants are effective for AD because they aid in reducing the free radicals that damage the brain cells (Howes and Houghton, 2012). Probiotics have been reported for their efficacy to enhance memory (Lyte, 2011). Probiotics are used as antidepressant in AD. It reduces anxiety like behavior and attenuates psychological stress. Neurochemicals are produced by microbes. Immunological and neurological effects are induced by probiotics. Probiotics also have immunomodulating activity (Misra and Medhi, 2013).

\subsubsection{Treatment using Medicinal Plants}

\subsubsection{Management of Alzheimer's disease}

Alzheimers disease is a neurodegenerative condition and the most well-known reason for dementia in the old. Despite the fact that the focal point of doctors is the administration of cholinesterase inhibitors in managing AD, it is vital that doctors build up a worldwide administration procedure for their patients. Early and accurate diagnosis of AD helps the patient and physician to manage the disease at onset.

\subsubsection{Drug Therapy}

This class of medication is presently regarded as the standard treatment of AD. There are four cholinesterase inhibitors which have been approved by the U.S. Food and Drug Administration (FDA) for the treatment of mild to moderate AD. These inhibitors increase the concentration of acetylcholine and the duration of its action in synapses by inhibiting the degradation of acetylcholine. There is also accumulating evidence that cholinesterase inhibitors may improve behavioral and psychological symptoms of $\mathrm{AD}$, such as psychosis and apathy (Cummings, 2000).

\subsubsection{Tacrine}

Tacrine was the first cholinesterase inhibitors to be endorsed specifically for the symptomatic treatment of patients with mild to moderate AD. The beginning portion for tacrine is $10 \mathrm{mg}$ at 4 times daily, and this dose is increased by $40 \mathrm{mg}$ /day for up to 4 weeks (according to tolerance), to a maximum daily dose of $160 \mathrm{mg}$ ( $40 \mathrm{mg} 4$ times daily). Tacrine has been associated with hepatotoxicity (Watkins et al., 1994) and thus requires baseline and multiple follow-up liver enzyme determinations.

Tacrine is extensively metabolized by the liver via the cytochrome P450 1A2 isoenzyme system; therefore, it has the potential to interact with other medications metabolized by this isoenzyme, such as theophylline, fluvoxamine, and cimetidine. Tacrine should be avoided in patients with liver disease.

\subsubsection{Donepezil}

Donepezil was the second cholinesterase inhibitor approved by the FDA for symptomatic treatment of mild to moderate AD in the United States. Donepezil is largely metabolized by the liver, although some of the dose is recovered in the urine as unchanged drug (11-17\%) (Dooley et al., 2000). Clinically relevant drug interactions with other drugs have not been extensively studied. Interaction with paroxetine (patient developing increased confusion and agitation) has been reported (Carrier, 1999). Caution should be exercised in using donepezil in patients with severe hepatic or renal disease.

\subsubsection{Rivastigmine}

This was the third cholinesterase inhibitor approved by the FDA for symptomatic treatment of mild to moderate $\mathrm{AD}$ in the United States. Rivastigmine should be titrated every 4 weeks, as opposed to every 2 weeks, as recommended when the drug was first made available. One unique feature of rivastigmine that distinguishes it from other cholinesterase inhibitors is the very low risk of drug interactions in AD patients receiving multiple medications . This is because the metabolism of rivastigmine occurs primarily via enzymatic cleavage (hydrolysis) by cholinesterases at the site of action and does not require the cytochrome P450 enzyme system.

\subsubsection{Galantamine}

This was the fourth cholinesterase inhibitor approved by the FDA for symptomatic treatment of mild to moderate $\mathrm{AD}$ in the United States. Metabolism is hepatic via glucuronidation and the cytochrome P450 isoenzymes; interactions with other drugs that are metabolized through this pathway are therefore possible. Caution should be used in patients with liver disease. The starting dose is $4 \mathrm{mg}$ twice a day, and this dose is increased every 4 weeks. The therapeutic dose is 16-24 mg/day. A 6-month study showed no additional benefit and a higher rate of side effects with a dose of $32 \mathrm{mg} /$ day (Raskind et al., 2000).

\subsection{Medicinal Plants Used in Treating AD in Africa}

Plants provide wealth of bioactive compounds, which exert a substantial strategy for the treatment of neurological disorders such as Alzheimer's disease (Carpinella et al., 2009). In the light of this fact, polyphenolic compounds from vegetables and plants have been exploited because of their potential antioxidative properties ( Ak and Gulcin, 2008). Since there has been growing focus on traditional herbal medicines presently due to the failure of existing treatments, we therefore provide an insight into the therapeutic avenue of medicinal plants used in Africa for 
treatment of Alzheimer's disease.

\subsubsection{Drumstick Tree (Moringa oleifera)}

Moringa Oleifera (MO), a plant from the family Moringacea is a major crop in Africa and Asia (Padayachee and Baijnath, 2012). MO is grown for its nutritious pods, edible leaves and flowers and can be utilized as food, medicine, cosmetic oil or forage for livestock. Its height rangesfrom 5 to $10 \mathrm{~m}$ (Padayachee and Baijnath, 2012). MO has been recognized as containing a great number of bioactive compounds (Saini et al., 2016; Martin et al., 2013). The most used parts of the plant are the leaves, which are rich in vitamins, carotenoids, polyphenols, phenolic acids, flavonoids, alkaloids, glucosinolates, isothiocyanates, tannins and saponins (Leone et al., 2015). The roots, bark, gum, fruit (pods), flowers, seed, and seed oil of MO are reported to have various biological activities, including protection against antidiabetic (Oyedepo et al., 2013), hypotensive (Faizi et al., 1998) and anti-inflammatory effects (Rao et al., 1998). MO leaves also protect against oxidative stress (Anwar et al., 2007), inflammation (Mahajan et al., 2009), hepatic fibrosis (Hamza, 2010), liver damage (Pari and Kumar, 2002), hypercholesterolemia (Halaby et al., 2013; Okwari et al., 2013), bacterial activity (Walter et al., 2011), cancer (Anwar et al., 2007), and liver injury (Efiong et al.,2013). The enormous number of bioactive compounds might explain the therapeutic properties of MO leaves.

Moringa Oleifera contains significant antioxidant properties and might be used to protect against neurological disorders. For example, MO leaf extract contains vitamin A (Ferreira et al., 2008) which can prevent oxidative stress through its antioxidant properties and enhance memory through nootropics activities. The extract of MO leaves also contains tannins, saponins, flavonoids, terpenoids and glycosides, which have medicinal properties. These compounds have been shown to be effective antioxidants, anti-carcinogenic agents and anti-inflammatory properties (Ayoola et al., 2008; Davinelli et al.,2015). Since oxidative stress, neuroinflammation, and calcium homeostasis disturbances are components of Alzheimers brains that lead to increased in A $\beta$ production, MO which has agents with multiple antioxidative components could be a possible therapeutic option for this disease.

\subsubsection{Tumeric (Curcuma longa)}

Turmeric is a sterile plant and does not produce any seeds. The underground rhizomes or roots of the plant are used for medicinal and food preparation. The rhizome is an underground stem that is thick and fleshy ringed with the bases of old leaves. Rhizomes are boiled and then dried and ground to make the distinctive bright yellow spice, turmeric.

A study conducted at UCLA found that curcumin may help the macrophages to clear the amyloid plaques found in Alzheimer's disease. The most prominent characteristic feature in AD is the presence of beta-amyloid plaques. These plaques are basically an accumulation of small fibers called beta amyloid fibrils. Because the deposition of betaamyloid protein is a consistent pathological hallmark of brains affected by $\mathrm{AD}$, the inhibition of A-beta generation, prevention of A-beta fibril formation, destabilization of pre-formed A-beta would be an attractive therapeutic strategy for the treatment of AD. Curcumin has been shown to increase the phagocytosis of amyloidbeta, effectively clearing them from the brains of patients with AD (Fiala et al., 2007).

Macrophages play an important role in the immune system. They help the body to fight against foreign proteins and then effectively clear them. Curcumin was treated with macrophages in blood taken from nine volunteers: six AD patients and three healthy controls. Beta amyloid was then introduced. The AD patients, whose macrophages were treated with curcumin, when compared with patients whose macrophages were not treated with curcumin, showed an improved uptake and ingestion of the plaques. Thus, curcumin may support the immune system to clear the amyloid protein (Zhang et al., 2006).

One of the important pathogenesis in Alzheimer's disease is the chronic inflammation of nerve cells.

Several studies have demonstrated the associated inflammatory changes such as microgliosis, astrocytosis and the presence of pro-inflammatory substances that accompany the deposition of amyloid- $\beta$ (A $\beta$ ) peptide. Patients with the prolonged use of certain nonsteroidal anti-inflammatory (NSAID) drugs such as ibuprofen have been shown to have a reduced risk of developing the symptoms of AD; however, the chronic use of NSAID can cause a toxic effect on the kidneys, liver and GI track.

Curcumin has a potent anti-inflammatory effect. Through its various anti-inflammatory effects, it may have a role in the cure of AD caused by oxidation and inflammation (Frautschy and Hu,2001).

\subsubsection{Aged Garlic Extract (Allium sativum)}

Garlic and its preparations have been widely recognized as agents for prevention and treatment of cardiovascular and other metabolic diseases, atherosclerosis, hyperlipidemia, thrombosis, hypertension, dementia, cancer and diabetes (Lawson, 1998). The medicinal use of garlic has a long history. Over the centuries, garlic has acquired a special position in the folklore of many cultures as a formidable prophylactic and therapeutic medicinal agent (Moyer, 1996). Garlic has attracted particular attention of modern medicine because of its widespread use around the world and the cherished belief that it helps to maintain good health by warding off illness and providing more vigor.

The health benefits of garlic as a neuroprotective agent are beginning to emerge (Carmia, 2006). Raw garlic homogenate has been the major preparation of garlic subjected to intensive scientific study, because it is the most 
common method of garlic consumption. Raw garlic homogenate is essentially the same as the aqueous garlic extract which has been used in various scientific studies. Allicin (allyl 2-propene thiosulfinate or Diallylthiosulfinate was long thought to be the principal bioactive compound present in aqueous extract or raw garlic homogenate( Augusti and Mathew, 1975). When garlic is chopped or crushed, allinase enzyme, present in garlic is activated and acts on alliin (present in whole garlic) to produce allicin (Fenwick and Hanley, 1985). Other important sulfur-containing compounds present in garlic homogenate are allyl methyl thiosulfonate, 1-propenyl allylthiosulfonate and -L-glutamyl-S-alkyl-L-cysteine (block, 1985). The enzyme allinase responsible for converting alliin (S-allylcysteine sulfoxide) to allicin is inactivated by heat (Lawson, 1998). Thus the water extract of heat treated garlic contains primarily alliin.

AGE has the potential to protect the brain against neurodegenerative conditions (Brown and Gwebu, 2003) by preventing brain injury following ischemia (Numagami et al., 1996), protecting neuronal cells against apoptosis (Brown and Gwebu, 2003; Mbyirukira and Gwebu, 2003; Kasuga et al., 2001), and preventing $\beta$-amyloid-induced oxidative death (Griffin et al., 1998). Moreover, treatment with AGE or S-allyl cysteine has been shown to prevent the degeneration of the brain's frontal lobe, improve learning and memory retention, and extend lifespan (Nishiyama et al.,1997).

\subsubsection{Cattle stick (Carpolobia lutea)}

Carpolobia lutea is a perennial shrub native to West and Central Tropical Africa. It is widely distributed in rainforests and the Guinea savannah of Sierra Leone, Cameroon and Nigeria. Extracts and fractions of C. lutea have hitherto only been reported anecdotally to possess benefits to cognition, with the study of C. lutea that has included an examination of its antidiarrheal (Nwidu, Essien et al., 2011), anti-nociceptive (Nwidu,Nwafor et al. 2011) and gastro-protective effects (Nwidu et al.2014).

The presence of secondary metabolites such as polyphenols and flavonoids compounds that include flavones and isoflavones exhibiting scavenging (antioxidant) activities in Carpolobia lutea have been effective in delaying the progression of $\mathrm{AD}$. These antioxidants may counter free radical damage produced during metabolism and for which radical levels may be exacerbated in AD (Parihar and Hemnani 2004; Zhao and Zhao, 2013). A recent in vivo study by Ajiwhen and Bisong (2013) administered a low-dose (1500 mg/kg p.o.) of C. lutea root extract to mice and reported cognitive memory enhancing activity, and this may reflect the potent anti-AChE activity described herein. At this dose of C. lutea roots, no toxicity to mice was reported (Ajiwhen and Bisong 2013).

\subsubsection{Lemon Balm (Melissa officinalis)}

Melissa officinalis (MO, English: lemonbalm, Lamiaceae), one of the oldest and still most popular aromatic medicinal plants, is used in phytotherapy for the prevention and treatment of nervous disturbances of sleep and gastrointestinal disorders as sedative and antispasmodic medicine. New neuropharmacological investigations showed that ethanol extracts of $M O$ exerted also neuroprotective (Bayat et al.,2012; Kamdem et al., 2013), antioxidant, cyclooxygenase-2 inhibitory(Lin et al., 2012), and antinociceptive activities (Kamdem et al., 2013; Guginski, 2009). Moreover, it is known that $M O$ is used for memory-enhancing effects in European folk medicine (Perry et al., 1996; Perry et al., 1999; Orhan and Aslan,2009).

Indeed, Akhondzadeh et al. (Akhondzadeh et al., 2003) carried out the clinical trial in which $M O$ extract produced a significantly better outcome on cognitive function than placebo in patients with mild to moderate Alzheimer's disease. $M O$ is traditionally used in treating neurological disorders through its anti-AChE (Soodi et al.,2014) and antiagitation properties (Abuhamdah et al., 2008). Moreover, Wake et al.( Wake et al., 2000) and Kennedy et al. (Kennedy et al., 2003) showed that $M O$ extract has nicotinic

receptor activity and that it can displace $[3 \mathrm{H}]-(N)$-nicotine from nicotinic receptors in homogenates of human cerebral cortex tissue and they suggested that these mechanisms can explain activity of $M O$ extract in amnesia model. This plant extract is a complex mixture, and its action may be a result of the summation of activities of several components (synergism/additive action of caffeic acid with salvianolic acids, rosmarinic acid, and others). 1.7.6 Garden Sage (Salvia officinalis)

Salvia officinalis comes from the Latin word meaning 'to heal' and is widely used in both culinary and medicinal preparations. Many species of Salvia are native to Mediterranean Europe and have been traditionally used for the treatment of a range of problems including digestive and circulation disturbances, bronchitis, coughs, asthma, memory problems, angina, mouth and throat inflammation, depression and excessive sweating. Salvia plants are traditionally noted for their antioxidant effects and ability to enhance 'head and brain' function, improve memory, quicken the senses, and delay age-associated cognitive decline (Perry et al., 1999). Salvia plants are a rich source of polyphenol compounds with over 160 identified polyphenols, comprising an array of phenolic acids and flavonoids. These phenolic compounds include caffeic acid and its derivatives, rosmarinic acid, salvianolic acids, sagecoumarin, lithospermic acids, sagernic acid, and yunnaneic acids. The most prevalent flavonoids include luteolin, apigenin, hispidulin, kaempferol and quercetin (Lu and Foo, 2002). Plants of the genus Salvia are also rich in essential oils, with a large array of terpenoids including a and b-thujone, camphor, 1,8-cineole, a-humulene, b-caryophyllene and viridiflorol. Moreover, they are rich sources of diterpenes and triterpenes such as carnosic acid, ursolic acid, carnosol and tanshinones. 
In vitro and animal studies have revealed that several Salvia species and their constituents are effective AChE inhibitors. An aqueous extract of S. officinalis lowered AChE activity in mice (Smash et al., 2015), and in vitro analyses revealed that ethanolic extracts of S. officinalis reduced AChE, with greater effects on butyrylcholinesterase (Kennedy et al., 2006; Scholey et al., 2008). AChE inhibition has also been observed from the phenolic diterpenes, 7amethoxyrosmanol and isorosmanol, isolated from S. officinalis (Sallam et al., 2016). The active constituents, rosmarinic acid, carnosic acid and quercetin, found in several Salvia species can also inhibit AChE activity (Sallam et al., 2016; Merad et al.,2014; Marcelo et al., 2013)

\subsection{Conclusion}

The prevalence of neurodegenerative disease such as Alzheimer's disease is increasing due to an ever ageing population; however treatment of this disease is still limited. An herbal approach of systematic screening of natural plants is a cost effective strategy of developing novel drug treatments. Thus, these plants remain a potentially beneficial pharmacotherapy in Africa that could be further developed for the treatment of AD and/or other neurodegenerative diseases such as Parkinson's disease to address these cholinergic deficits.

\section{REFERENCES.}

Abuhamdah, S., Huang, L., Elliott, J. "Pharmacological profile of an essential oil derived from Melissa officinalis with anti-agitation properties: focus on ligand-gated channels," Journal of Pharmacy and Pharmacology, vol. 60, no. 3, pp. 377-384, 2008.

Ajiwhen, I.O. and Bisong, S.A. 2013. Effect of ethanolic extract of Carpolobia lutea (Polygalaceae) root on learning and memory in CD1 mice. Niger J Physiol Sci. 28:141-145.

Akhondzadeh, S., Noroozian, M., Mohammadi, M., Ohadinia, S., Jamshidi, A.H. and Khani, M. "Melissa officinalis extract in the treatment of patients with mild to moderate Alzheimer's disease: a double blind, randomised, placebo controlled trial," Journal of Neurology Neurosurgery and Psychiatry, vol. 74, no. 7, pp. 863-866, 2003.

Anwar, F., Latif, S., Ashraf, M. and Gilani, A.H. Moringa oleifera: A food plant with multiple medicinal uses. Phytother. Res. 2007, 21, 17-25.

Asgari M.M., Maruti S.S., Kushi L.H., White E. (2009). Antioxidant supplementation and risk of incident melanomas: results from a large prospective cohort study. Arch Dermatol, 145(8): 879-882

Atawodi S.E. (2011). Nigerian foodstuffs with prostate cancer chemopreventive polyphenols. Infect agent cancer, 6(2): S9

Augusti, K. T. and Mathew, P. T. Effect of allicin on certain enzymes of liver after a short term feeding to normal rats. Experentia 1975; 31:148-149

Aung H.H., Mehendale S.R., Wang C.Z., Xie J., McEntee E. (2007). Cisplatin's tumoricidal effect on human breast carcinoma MCF-7 cells was not attenuated by

Ayoola, G.A., Coker, H.A., Adesegun, S.A., Adepoju-Bello, A.A., Obaweya, K. and Ezennia, E.C. Phytochemical screening and antioxidant activities of some selected medicinal plants used for malaria therapy in southwestern Nigeria. Trop. J. Pharm. Res. 2008, 7, 1019-1024.

Barreira J.C.M., Ferreira I.C.F.R., Oliveira M.B.P.P., Pereira J.A. (2008). Antioxidant activities of the extracts from chestnut flower, leaf, skins and fruit. Food Chem, 107: 1106-1113

Bayat, M., Tameh, A.A. and Ghahremani M.H. "Neuroprotective properties of Melissa officinalis after hypoxicischemic injury both in vitro and in vivo," DARU Journal of Pharmaceutical Sciences, vol. 20, article 42, 2012.

Block E. Chemistry of garlic and onions. Sci. Am. 1985; 252:94-99

Boileau T.W., Liao Z., Kim S., Lemeshow S., Erdman J.W. Jr., Clinton S.K. (2003).

Brasky T.M., Kristal A.R., Navarro S.L., Lampe J.W., Patterson R.E., Peters U., White E. (2011). Specialty supplements and prostate cancer risk in the VITamins And

breast cancer risk- a population based case-control study in Canada. BMC Cancer, 11:

breast cancer risk. J Nutr, 139(2): 310-316

Brown, C. and Gwebu, E.T. Effect of aged garlic extract on caspase-3 activity in PC12 cells. J. Ala. Acad. Sci. 2003, 74, 132-133.

Capanoglu E., Bovy A., Battino M. (2008). Antioxidants, phenolic compounds, and carcinoma growth via intrinsic apoptotic pathway. World J Gastroenterol, 17(31): 3605- 3613

Carmia, B. Garlic reduces dementia and heart disease risk. Journal of Nutrition 2006; 136:810S-812S

Carpentera C.L., Yu M.C., London S.J. (2009). Dietary isothiocyanates, Glutathione STransferase M1 (GSTM1), and lung cancer risk in African Americans and Caucasians from Los Angeles County, California. Nutr Cancer, 61(4): 492-499 Cells. Clin Cancer Res, 15(15): 4895-4903

Chang-Claude J. (2008). Serum 25-hydroxyvitamin D and risk of post-menopausal Chauhan, N.B. and Sandoval, J. Amelioration of early cognitive deficits by aged garlic extract in Alzheimer's transgenic mice. 
Phytother.Res. 2007; 21:629-640

Chen Y., Xu Y., Zhu Y., Li X. (2013). Anti-Cancer Effects of ginsenoside compound k on pediatric acute myeloid leukemia cells. Cancer Cell Int, 13: 24

CNS nicotinic and muscarinic receptor-binding properties," Neuropsychopharmacology, vol. 28, no. 10, pp. 1871$1881,2003$.

cocoa products on bowel habits in healthy subjects: a free-living, two-stage, randomized, crossover, single-blind intervention. Nutrition \& Metabolism, 9: 33

Cole B.F., Baron J.A., Sandler R.S., Haile R.W., Ahnen D.J., Bresalier R.S. et al., colorectal cancer cell line. Cancer Res Treat, 43(1): 49-55

Coyle C.H., Philips B.J., Morrisroe S.N., Chancellor M.B., Yoshimura N. (2008).

Davinelli, S., Bertoglio, J.C., Zarrelli, A., Pina, R. and Scapagnini, G. A randomized clinical trial evaluating the efficacy of an anthocyanin-maqui berry extract (Delphinol) on oxidative stress biomarkers. J. Am. Coll. Nutr. 2015, 34 (Suppl. 1), 28-33.

detected by NMR spectroscopy. Chemistry. 2013;19(21):6641-9.

determination of ellagic acid content in chestnut bark and fruit. Food Chem, 110: 1007- 1011

disease. Oxid Med Cell Longev. 2013:316523.

Efiong, E.E., Igile, G.O., Mgbeje, B.I., Out, E.A. and Ebong, P.E. Hepatoprotective and anti-diabetic effect of combined extracts of Moringa oleifera and Vernoniaamygdalina in streptozotocin-induced diabetic albino Wistar rats. J. Diabetes Endocrinol. 2013, 4, 45-50.

ethnopharmacology, phytochemistry and pharmacology of Moringa oleifera Leaves: An overview. Int. J. Mol.Sci. 2015, 16, 12791-12835.

Faizi, S., Siddiqui, B., Saleem, R., Aftab, K., Shaheen, F. and Gilani, A. Hypotensive constituents from the pods of Moringa oleifera. Planta Med. 1998, 64, 225-228.

Fenwick, G. R. and Hanley, A. B. The genus Allium. Part 2. Crit.Rev. FoodSci. Nutr 1985; 22:273-377

Ferreira, P.M., Farias, D.F., Oliveira, J.T. and Carvalho, A.D. Moringa oleifera: Bioactive compounds and nutritional potential. Rev. Nutr. 2008, 21, 431-437.

Fiala, M., Liu, P.T., Espinosa-Jeffrey, A., Rosenthal, M.J., Bernard, G. and Ringman, J.M. Innate immunity and transcription of MGAT-III and Toll-like receptors in Alzheimers disease patients are improved by bisdemethoxycurcumin. Proc Natl Acad Sci USA. 2007;104:12849-54.

Finkel T., Holbrook N.J. (2000). Oxidants, oxidative stress and the biology of ageing.

Folate, Methionine, and Vitamins B-12, B-6 and Prostate Cancer Risk in American Veterans. J Cancer Epidemiol. doi:10.1155/2012/957467 -32

Frautschy, S.A. and $\mathrm{Hu}, \mathrm{W}$. Phenolic anti inflammatory antioxidant reversal of $\mathrm{b}$ induced cognitive deficits and neuropathology. Neurobiol Aging. 2001;22:993-1005.

Gifkins D., Olson S.H., Paddock L., King M., Demissie K., Lu S., Kong A.T., Rodriguez-Rodriguez L., Bandera E.V. (2012). Total and individual antioxidant intake and risk of epithelial ovarian cancer. BMC Cancer, 12: 211

Griffin, W.S., Sheng, J.G., Royston, M.C., Gentleman, S.M., McKenzie, J.E., Graham, D.I., Roberts, G.W. and Mrak, R.E. Glial-neuronal interactions in Alzheimer's disease: The potential role of a 'cytokine cycle' in disease progression. Brain Pathol. 1998, 8, 65-72.

Guginski, G., Luiz, A.P. and Silva M.D. "Mechanisms involved in the antinociception caused by ethanolic extract obtained from the leaves of Melissa officinalis (lemon balm) in mice,"

Guha N., Kwan M.L., Quesenberry Jr C.P., Weltzien E.K., Castillo A.L., Caan B.J.

Gupta S., Hastak K., Ahmad N., Lewin J.S., Mukhtar H. (2008). Inhibition of prostate carcinogenesis in TRAMP mice by oral infusion of green tea polyphenols. Proc Natl Acad Sci, 98: 10350-10355

Halaby, M.S., Metwally, E.M. and Omar, A.A. Effect of Moringa oleifera on serum lipids and kidney function of hyperlipidemic rats. J. Appl. Sci. Res. 2013, 9, 5189-5198.

Halliwell B. (1994). Free radicals, antioxidants, and human disease: curiosity, cause, or consequence? Lancet, 344(8924): 721-724

Hamza, A.A. Ameliorative effects of Moringa oleifera Lam seed extract on liver fibrosis in rats. Food Chem. Toxicol. 2010, 48, 345-355.

Hannum S.M. (2004). Potential impact of strawberries on human health: a review of the science. Crit Rev Food Sci Nutr, 44(1): 1-17

He N.W., Zhao Y., Guo L., Shang J., Yang X.B. (2012). Antioxidant, antiproliferative, and pro-apoptotic activities of a saponin extract derived from the roots of Panax notoginseng (Burk.) F.H. Chen. J Med Food, 15 (4): 350-359

Hirvonen T., Kontto J., Jestoi M., Valsta L., Peltonen K., Pietinen P., Virtanen S.M.,

Hirvonen T., Kontto J., Jestoi M., Valsta, L., Peltonen, K., Pietinen, P., Virtanen, S.M., Sinkko, H., KronbergKippilä, C., Albanes, D., Virtamo, J. (2010). Dietary Acrylamide Intake and the Risk of Cancer Among 
Finnish Male Smokers. Cancer Causes Control, 21(12): 2223-2229

Hotaling J.M., Wright J.L., Pocobelli G., Bhatti P., Porter M.P., White E. (2011). Longterm use of supplemental vitamins and minerals does not reduce the risk of urothelial cell carcinoma of the bladder in the VITamins And Lifestyle Study. J Urol, 185(4): 1210-1215

Huang W., Zhang H, Liu W, Li C. (2012). Survey of antioxidant capacity and phenolic composition of blueberry, blackberry, and strawberry in Nanjing. J Zhejiang Univ-Sci B (Biomed \& Biotechnol), 13(2): 94-102

Hwang C.S., Kwak H.S., Lim H.J., et al. (2006). Isoflavone metabolites and their in implication for cancer prevention. Nutr Rev, 66: 667-683

inhibition of oxidative stress and protection of immune system. Mol Nutr Food Res, intake and the risk of cancer among Finnish male smokers. Cancer Causes Control,

Intakes of plant foods, fibre and fat and risk of breast cancer - a prospective study in the Malmo“ Diet and Cancer cohort. British Journal of Cancer, 90: 122-127 interventions. J Clin Neurosci. 11:456-467.

Iwasaki M., Inoue M., Sasazuki S., Miura T. et al. (2010). Plasma tea polyphenol levels and subsequent risk of breast cancer among Japanese women: A Nested Case-Control Study. Breast Cancer Res Treat, 124(3): 82734

Jackson, R., McNeil, B., Taylor, C., Holl, G., Ruff, D. and Gwebu, E. Effect of aged garlic extract on human recombinant caspace-3 activity. J. Ala. Acad. Sci. 2003, 74, 121-122.

Jiang J, Chen X, Chen X, Zheng S. (2011). Ginsenoside Rg3 inhibit hepatocellular

Jin Y., Kotakadi V.S., Ying L., Hofseth A.B., Cui S., Wood P.A., Windust A., Matesic L.E., Pena E.A., Chiuzan C., Singh N.P., Nagarkatti M., Nagarkatti P.S., Wargovich M.J., Hofseth L.J. (2008). American ginseng suppresses inflammation and DNA damage associated with mouse colitis. Carcinogenesis, 29: 2351-2359 Journal of Ethnopharmacology, vol. 69, no. 2, pp. 105-114, 2000.

Kamdem, J.P., Adeniran, A. and Boligon A.A. "Antioxidant activity, genotoxicity and cytotoxicity evaluation of lemon balm (Melissa officinalis L.) ethanolic extract: Its potential role in neuroprotection," Industrial Crops and Products, vol. 51, pp. 26-34, 2013.

Kasuga, S., Uda, N., Kyo, E., Ushijima, M., Morihara, N. and Itakura, Y. Pharmacologic activities of aged garlic extract in comparison with other garlic preparations. J. Nutr. 2001, 131, 1080S-1084S.

Katiyar S.K. (2008). Grape seed proanthocyanidines and skin cancer prevention:

Kennedy D.O., Pace S, Haskell C, Okello E.J., Milne A, Scholey A.B. Effects of cholinesterase inhibiting sage (Salvia officinalis) on mood, anxiety and performance on a psychological stress or battery. Neuropsychopharmacology. 2006;31(4):845-52.

Kennedy D.O., Wake, G., Savelev, S. "Modulation of mood and cognitive performance following acute administration of single doses of Melissa officinalis (Lemon balm) with human

Khan S.A., Chatterton R.T., Michel N., Bryk M., Lee O., Ivancic D. et al. (2012). Soy isoflavone supplementation for breast cancer risk reduction: A Randomized Phase II Trial. Cancer Prev Res (Phila), 5(2): 309-319

King M.L., Murphy L.L. (2010). Role of cyclin inhibitor protein p21 in the inhibition of HCT116 human colon cancer cell proliferation by American Ginseng (Panax quinquefolius) and its Constituents. Phytomedicine, 17(3-4): 261

Lawson, L.D. Garlic: a review of its medicinal effects and indicated active compounds. Phytomedicines of Europe. Chemistry and Biological activity. 1998; series 691:176-209

Lee S., Shu X., Li H., Yang G., Cai H., Wen W., Ji B., Gao J., Gao Y., Zheng W.

Lee S.H., Kim E.J., Kim S.H. (2011). Chestnut extract induces apoptosis in AGS human gastric cancer cells. Nutr Res Pract, 5(3): 185-191

Leone, A., Spada, A., Battezzati, A., Schiraldi, A., Aristil, J. and Bertoli, S. Cultivation, genetic,

Li J., Zhang D., Stoner G.D., Huang C. (2008). Differential effects of black raspberry and strawberry extracts on BaPDE-induced activation of transcription factors and their target genes. Mol Carcinogenesis, 47: 286-294

Lin, J.T., Chen, Y.C., Lee, Y.C., Hou, R., Chen, F.L. and Yang, D.J. "Antioxidant, anti-proliferative and cyclooxygenase-2 inhibitory activities of ethanolic extracts from lemon balm

Liu Z., Li X., Simoneau A.R., Jafari M., Zi X. (2012). Rhodiola rosea extracts and

Lu Y, Foo LY. Polyphenolics of Salvia - a review. Phytochemistry. 2002;59(2):117-40.lycopene and tomato extract supplementations inhibit Nonalcoholic Steatohepatitis

Mahajan, S.. Banerjee, A., Chauhan, B., Padh, H., Nivsarkar, M. and Mehta, A. Inhibitory effect of N-butanol fraction of Moringa oleifera Lam seeds on ovalbumin-induced airway inflammation in a guinea pig model of asthma. Int. J. Toxicol. 2009, 28, 519-527.

Marcelo F, Dias C, Martins A, Madeira PJ, Jorge T, Florencio M. Molecular recognition of rosmarinic acid from Salvia sclareoides extracts by acetylcholinesterase: a new binding site

Martin, C., Martin, G., Garcia, A., Fernández, T., Hernández, E. and Puls, L. Potential applications of Moringa oleifera. A critical review. Pastosy Forrajes 2013, 36, 150-158

Mbyirukira, G. and Gwebu, E.T. Aged garlic extract protects serum deprived PC12 cells from apoptosis. J. Ala. 
Acad. Sci. 2003, 74, 127-128.

McCormick D.L., Rao K.V.N., Johnson W.D., Bosland M.C., Lubet R.A., Steele V.E. (2010). Null activity of selenium and vitamin $\mathrm{E}$ as cancer chemopreventive agents in the rat prostate. Cancer Prev Res (Phila), 3(3): 381-392

Mein J.R., Lian F., Wang X.D. (2008). Biological activity of lycopene metabolites: melanoma cell migration via the Phosphatidylinositol 3-kinase/Akt/Rac1 signal pathway. Experimental and mol Med, 40(5): 486-494

Merad M, Soufi W, Ghalem S, Boukli F, Baig MH, Ahmad K. Molecular interaction of acetylcholinesterase with carnosic acid derivatives: a neuroinformatics study. CNS Neurol Disord Drug Targets. 2014;13(3):440-6.

Messina M., Hilakivi-Clarke L. (2009). Early intake appears to be the key to the metabolism, and the risk of gallbladder cancer in Chilean women. World J Gastroenterol, 16(3): 372-378

Moncayo R., Kroiss A., Oberwinkler M., Karakolcu F., Starzinger M., Kapelari K.,

Mondu A.M., Weinstein S.J., Männistö S., Snyder K (2010). Serum Vitamin D and Risk of Bladder Cancer. Cancer Res, 70(22): 9218-9223

Moselhy S.S., Al Mslmani M.A. (2008). Chemopreventive effect of lycopene alone or with melatonin against the genesis of oxidative stress and mammary tumors induced by 7,12 dimethyl(a)benzanthracene in Sprague Dawely female rats. Mol Cell Biochem, 319: 175-180

Moyers, S. Garlic in Health, History and World Cuisine. Suncoast Press, St Petersburg, FL 1996: 1-36 Nature, 408(6809): 239-247

Neuhouser M.L., Barnett M.J., Kristal A.R, Ambrosone C.B., King I.B., Thornquist M., Goodman G.G. (2009). Dietary supplement use and prostate cancer risk in the carotene and retinol efficacy trial. Cancer Epidemiol Biomarkers Prev, 18(8): 2202-2206

Nishiyama, N., Moriguchi, T. and Saito, H. Beneficial effects of aged garlic extract on learning and memory impairment in the senescence-accelerated mouse. Exp. Gerontol. 1997, 32, 149-160.

Numagami, Y., Sato, S. and Ohnishi, S.T. Attenuation of rat ischemic brain damage by aged garlic extracts: A possible protecting mechanism as antioxidants. Neurochem. Int. 1996, 29, 135-143.

Nwidu, L.L., Nwafor, .PA., da Silva, V.C., Rodrigues, C.M., dos Santos, L.C., Vilegas,

Nwidu, L.L., Aprioku, J.S. and Guluye, F.H. 2014. Study on radical scavenging and gastroprotective effects of ethanolic stem-bark extract of Carbolobia lutea in rodents. W J Pharm Res. 3:73-88.

Nwidu, L.L., Essien, G.E., Nwafor, P.A. and Vilegas, W. 2011. Antidiarrheal mechanism of Carpolobia lutea leaf fractions in rats. Pharm Biol. 49:1249-1256.

Okwari, O., Dasofunjo, K., Asuk, A., Alagwu, E. and Mokwe, C. Anti-hypercholesterolemic and hepatoprotective effect of aqueous leaf extract of Moringa oleifera in rats fed with thermoxidized palm oil diet. J. Pharm. Biol. Sci. 2013, 8, 57-62.

Ollberding N.J., Lim U., Wilkens L.R., Wendy Setiawan V., Shvetsov Y.B., Henderson B.E., Kolonel L.N., Goodman M.T. (2012). Legume, soy, tofu, and isoflavone intake and endometrial cancer risk in postmenopausal women in the Multiethnic Cohort Study. J Natl Cancer Inst, 104: 67-76 -28

Orhan, I. and Aslan, M. "Appraisal of scopolamine-induced antiamnesic effect in mice and in vitro antiacetylcholinesterase and antioxidant activities of some traditionally used Lamiaceae

Oszmiański J., Wojdyło A. (2009). Comparative study of phenolic content and antioxidant activity of strawberry puree, clear, and cloudy juices. Eur Food Res Technol, 228(4): 623-631.

Oyedepo, T.A., Babarinde, S.O. and Ajayeoba, T.A. Evaluation of the antihyperlipidemic effect of aqueous leaves extract of Moringa oleifera in alloxan induced diabetic rats. Int. J. Biochem. Res. Rev. 2013, 3, 162-170.

Özten-Kandaş N., Bosland M.C. (2011). Chemoprevention of prostate cancer: natural Padayachee, B. and Baijnath, H. An overview of the medicinal importance of Moringaceae. J. Med. Plants Res. 2012, 6, 5831-5839.

Pan S.Y., Zhou J., Gibbons L., Morrison H., and Wen S.W. (2011). Antioxidants and

Pandey M., Verma R.K., Saraf S.A. (2010). Nutraceuticals: new era of medicine and health. Asian J Pharm Clin Res, 3: 11-15

Pari, L. and Kumar, N.A. Hepatoprotective activity of Moringa oleifera on antitubercular drug-induced liver damage in rats. J. Med. Food 2002, 5, 171-177.

Parihar, M.S. and Hemnani, T. 2004. Alzheimer's disease pathogenesis and therapeutic

Park D.H., Shin J.W., Park S.K. (2009). Diethylnitrosamine (DEN) induces

Perry E.K, Pickering AT, Wang WW, Houghton PJ, Perry NS. Medicinal plants and Alzheimer's disease: from ethnobotany to phytotherapy. J Pharm Pharmacol. 1999;51(5):527-34.

Perry, E.K., Pickering, A.T., Wang, W.W., Houghton, P.J. and Perry, N.S. "Medicinal plants and Alzheimer's disease: from ethnobotany to phytotherapy," Journal of Pharmacy and

Perry, N., Court, G., Bidet, N., Court, J. and Perry, E. "European herbs with cholinergic activities: potential in dementia therapy," International Journal of Geriatric Psychiatry, vol. 11, no. 12, pp. 1063-1069, 1996.

Peters U., Foster C.B., Chatterjee N., Schatzkin A. (2007). Serum selenium and risk of prostate cancer-a nested case control study. Am J Clin Nutr, 85(1): 209-217 
Pharmacology Biochemistry \& Behavior, vol. 93, no. 1, pp. 10-16, 2009.

Pharmacology, vol. 51, no. 5, pp. 527-534, 1999.

plants," Journal of Ethnopharmacology, vol. 122, no. 2, pp. 327-332, 2009.

Poudyal D., Le P.M., Davis T., Hofseth A.B., Chumanevich A., Chumanevich A.A (2017). Premenopausal Breast Cancer risk in a German case-control study. Int J Cancer, 124(1): 250-5

Rao, K.S. and Mishra, S.H. Anti-inflammatory and antihepatoxic activities of the roots of Moringa pterygosperma Gaertn. Indian J. Pharm. Sci. 1998, 60, 12-16.

Saini, R.K., Sivanesan, I. and Keum, Y.S. Phytochemicals of Moringa oleifera: A review of their nutritional, therapeutic and industrial significance. Biotech 2016, 6 .

Sallam A, Mira A, Ashour A, Shimizu K. Acetylcholine esterase inhibitors and melanin synthesis inhibitors from Salvia officinalis. Phytomedicine. 2016;23(10):1005-11.

Scholey AB, Tildesley NT, Ballard CG, Wesnes KA, Tasker A, Perry E.K. An extract of Salvia (sage) with anticholinesterase properties improves memory and attention in healthy older volunteers. Psychopharmacology (Berl). 2008;198(1):127-39.

Seeram N.P. (2008). Berry fruits: compositional elements, biochemical activities, and the impact of their intake on human health, performance, and disease. J Agric Food Chem, 56: 627-9

Shanghai Women's Health Study. America Journal Clinic Nutrition, 89: 1920-6

Shin D., Kim O., Jun H., Kang M. (2008). Inhibitory effect of capsaicin on B16-F10

Shrubsole M. J., Lu W., Chen Z. et al. (2009). Drinking green tea modestly reduces

Shu X.O., Zheng Y., Cai H., Gu K., Chen Z., Zheng W., et al. (2009). Soy food intake and breast cancer survival. JAMA. 302(22): 2437-2443

Singh S.V., Powolny A.A., Stan S.D., Xiao D., Arlotti J.A., Warin R., Hahm E.,

Sinkko H., Kronberg-Kippilä C., Albanes D., Virtamo J. (2010). Dietary acrylamide

Smach MA, Hafsa J, Charfeddine B, Dridi H, Limem K. Effects of sage extract on memory performance in mice and acetylcholinesterase activity. Ann Pharm Fr. 2015;73(4):281-8

Soodi, M., Naghdi, N., Hajimehdipoor, H., Choopani, S. and Sahraei, E. "Memory-improving activity of Melissa officinalis extract in na"1ve and scopolamine-treated rats," Research in Pharmaceutical Sciences, vol. 9, no. 2, pp. 107-114, 2014

Stan S.D., Singh S.V. (2009). Transcriptional Repression and Inhibition of Nuclear

survivors: Life After Cancer Epidemiology (LACE) Study. Breast Cancer Res Treat,

Talasz H., Moncayo H. (2008). The role of selenium, vitamin C, and zinc in benign thyroid diseases and of selenium in malignant thyroid diseases: Low selenium levels are found in subacute and silent thyroiditis and in papillary and follicular carcinoma. BMC Endocrine Disorders 8: 2

Tang L., Zirpoli G.R., Guru K., Moysich K.B., Zhang Y., Ambrosone C.B., McCann

Tang L., Zirpoli G.R., Jayaprakash V. (2010). Cruciferous vegetable intake is

Tu Y., Roberts L., Shetty K., Schneider S.S. (2008). Rhodiola crenulata induces death and inhibits growth of breast cancer cell lines. J Med Food, 11: 413-23

Tulipani S., Mezzetti B., Capocasa F., Bompadre S., Beekwilder J., de Vos C.H.R.,

use and risk of cutaneous squamous cell carcinoma. J Am Acad Dermatol, 65(6): 1145- 1151

Vidal A.C., Grant D.J., Williams C.D. (2012). Associations between Intake of

vitamin $\mathrm{E}$ transport genes with circulating vitamin E concentrations and prostate cancer risk. Cancer Res, 69(4): $1429-1438$

W. and Nunes-de-Souza, R.L. 2011. Anti-nociceptive effects of Carpolobia lutea (Polygalaceae) leaf fractions in animal models. Inflammopharmacology. 19:215-225.

Wake, G., Court, J., Pickering, A., Lewis, R., Wilkins, R. and Perry, E. "CNS acetylcholine receptor activity in European medicinal plants traditionally used to improve failing memory,"

Walter R.B., Brasky T.M., Milano F., White E. (2011). Vitamin, mineral, and specialty supplements and risk of hematologic malignancies in the prospective VITamins And Lifestyle (VITAL) study. Cancer Epidemiol Biomarkers Prev, 20(10): 2298-2308

Walter, A., Samuel,W., Peter, A. and Joseph, O. Antibacterial activity of Moringa oleifera and Moringa stenopetala methanol and N-hexane seed extracts on bacteria implicated in water borne diseases. Afr. J. Microbiol. Res. 2011, 5, 153-157.

Wang C., Aung H.H., Zhang B., Sun S., Li X., He H., Xie J., He T., Du W., Yuan C.

Wang C., Du G., Zhang Z., Wen X., Calway T., Zhen Z., Musch M.W., Bissonnette M., Chang E.B., Yuan C. (2012). Ginsenoside compound $\mathrm{K}$, not $\mathrm{Rb} 1$, possesses potential chemopreventive activities in human colorectal cancer. Int J Oncol, 40(6): 1970-1976

Wargovich M.J., Nagarkatti M., Nagarkatti P.S., Windust A., and Hofseth L.J. (2012).

Williams C.D., Satia J.A., Adair L.S., Stevens J (2010). Antioxidant and DNA

Wu A.H., Koh W.P., Wang R., Lee H.P., Yu M.C. (2008). Soy intake and breast cancer risk in singapore chinese 
health study. Br J Cancer, 99: 196-200

Yang G., Shu X.O., Li H., Chow W.H., Cai H., Zhang X., Gao Y.T., Zheng W. (2009). Prospective cohort study of soy food intake and colorectal cancer risk in women. America Journal Clinic Nutrition, 89: 577-583

Zeitouni N.C., Larson J., Stefanick M.L. (2011). Calcium Plus Vitamin D Supplementation and the Risk of Nonmelanoma and Melanoma Skin Cancer: Post Hoc Analyses of the Women's Health Initiative Randomized Controlled Trial. J Clin Oncology, 29: 3078-3084

Zhang M., Huang J., Xing X., Holman C.D. (2009). Dietary intake of mushrooms and green tea combine to reduce the risk of breast cancer in chinese women. Int J Cancer, 124: 1404-1408

Zhang, L., Fiala, M., Cashman, J., Sayre, J., Espinosa, A. Mahanian, M. Curcuminoids enhance amyloid -beta uptake by macrophages of Alzheimer's disease patients. J Alzheimers Dis. 2006;10:1-7.

Zhao, Y. and Zhao, B. 2013. Oxidative stress and the pathogenesis of Alzheimer's 